\title{
Online Quantification of Criegee Intermediates of $\alpha$-Pinene Ozonolysis by Stabilization with Spin Traps and Proton-Transfer Reaction Mass Spectrometry Detection
}

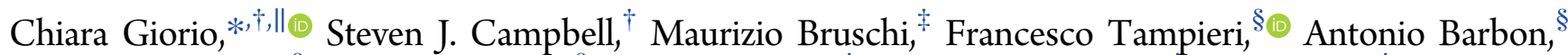
Antonio Toffoletti, ${ }^{\S}$ Andrea Tapparo, ${ }^{\S}$ Claudia Paijens, ${ }^{\dagger}$ Andrew J. Wedlake, ${ }^{\dagger}$ Peter Grice, ${ }^{\dagger}$ Duncan J. Howe, ${ }^{\dagger}$ and Markus Kalberer*, ${ }^{\dagger}$

${ }^{\dagger}$ Department of Chemistry, University of Cambridge, Lensfield Road, Cambridge, CB2 1EW, United Kingdom

${ }^{\ddagger}$ Dipartimento di Scienze dell’Ambiente e del Territorio e di Scienze della Terra, Università degli Studi di Milano Bicocca, Piazza della Scienza 1, Milano 20126, Italy

${ }^{\S}$ Dipartimento di Scienze Chimiche, Università degli Studi di Padova, via Marzolo 1, Padova 35131, Italy

\section{Supporting Information}

ABSTRACT: Biogenic alkenes, which are among the most abundant volatile organic compounds in the atmosphere, are readily oxidized by ozone. Characterizing the reactivity and kinetics of the first-generation products of these reactions, carbonyl oxides (often named Criegee intermediates), is essential in defining the oxidation pathways of organic compounds in the atmosphere but is highly challenging due to the short lifetime of these zwitterions. Here, we report the development of a novel online method to quantify atmospherically relevant Criegee intermediates (CIs) in the gas phase by stabilization with spin traps and analysis with proton-transfer

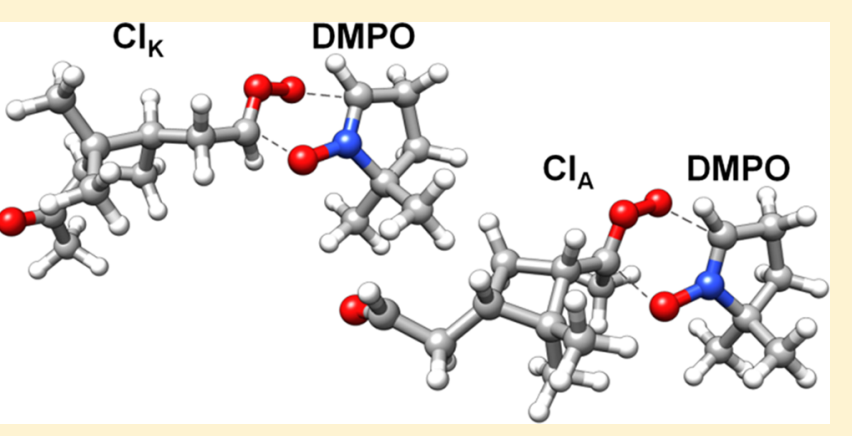
reaction mass spectrometry. Ozonolysis of $\alpha$-pinene has been chosen as a proof-of-principle model system. To determine unambiguously the structure of the spin trap adducts with $\alpha$-pinene CIs, the reaction was tested in solution, and reaction products were characterized with high-resolution mass spectrometry, electron paramagnetic resonance, and nuclear magnetic resonance spectroscopy. DFT calculations show that addition of the Criegee intermediate to the DMPO spin trap, leading to the formation of a six-membered ring adduct, occurs through a very favorable pathway and that the product is significantly more stable than the reactants, supporting the experimental characterization. A flow tube set up has been used to generate spin trap adducts with $\alpha$-pinene CIs in the gas phase. We demonstrate that spin trap adducts with $\alpha$-pinene CIs also form in the gas phase and that they are stable enough to be detected with online mass spectrometry. This new technique offers for the first time a method to characterize highly reactive and atmospherically relevant radical intermediates in situ.

\section{INTRODUCTION}

Atmospheric chemistry is driven by the oxidation of biogenic and anthropogenic volatile organic compounds, triggered mainly by $\bullet \mathrm{OH}, \mathrm{O}_{3}$, and $\bullet \mathrm{NO}_{3}$. ${ }^{1}$ One of the most important reactions in the troposphere is the ozonolysis of alkenes contributing to photochemical smog and global climate change. ${ }^{2}$ Ozonolysis of alkenes occurs with a generally accepted mechanism, proposed for the first time by Rudolf Criegee. ${ }^{3}$ According to the Criegee mechanism, ozone adds to the double bond of alkenes (1,3-cycloaddition of $\mathrm{O}_{3}$ across the $\mathrm{C}=\mathrm{C}$ double bond) forming a primary ozonide, which promptly decomposes into a long-lived carbonyl compound and a shortlived carbonyl oxide named Criegee intermediate (CI), Criegee biradical, or Criegee zwitterion, as the electronic structure may take multiple configurations. ${ }^{4-7}$ CIs further react rapidly through unimolecular, self-, and bimolecular reactions resulting in the formation of free radicals, organic acids, carbonyl compounds, and organic aerosols. ${ }^{2}$

Carbonyl oxide chemistry represents one of the large uncertainties in tropospheric chemistry, playing a pivotal role in our understanding of oxidation of hydrocarbons, $\mathrm{NOx}, \mathrm{SO}_{2}$, and other trace gases, ${ }^{2,5,8}$ thus playing a vital role in determining the oxidative capacity of the atmosphere and dominating night-time $\bullet \mathrm{OH}$ production in the troposphere. Reaction of carbonyl oxides with $\mathrm{SO}_{2}$ leading to formation of $\mathrm{H}_{2} \mathrm{SO}_{4}$, studied for the first time by Cox and Penkett, ${ }^{9}$ has been the center of attention also in recent studies, as the latter is a key compound in initiating particle nucleation and thus aerosol production in the troposphere, affecting global climate. ${ }^{1,10} \mathrm{CIs}$

Received: October 20, 2016

Published: February 16, 2017 
have also been involved in explaining the mechanisms of oligomerization in aerosol, ${ }^{11}$ which has recently been associated with cloud condensation nuclei activity and therefore indirect climate effects of aerosol. ${ }^{12}$

Recently, extremely low-volatile organic compounds (ELVOCs) have been discovered, which irreversibly condense into the particle phase, enhancing, and in some cases dominating, the early stage of atmospheric aerosol formation (nucleation), constituting a crucial link between new particle formation and cloud condensation nuclei formation. ${ }^{13,14}$ The suggested formation pathway of ELVOCs rely on initiation via ozonolysis of terpenes and therefore CI formation, followed by an autoxidation process involving molecular oxygen (vinylhydroperoxide pathway). ${ }^{13,15}$

The analysis of Criegee intermediates represents an analytical challenge due to their characteristic high reactivity and short lifetime. Despite decades of theoretical studies ${ }^{6,16-18}$ and indirect experimental evidence ${ }^{1,19-22}$ supporting the importance of Criegee radicals in the troposphere, it was only in 2008 that direct detection of the formaldehyde oxide, the simplest $\mathrm{CI}$, was reported through direct measurement. ${ }^{23}$ Moreover, in 2012 Welz et al. $^{24}$ showed that formaldehyde oxide could be formed directly from the reaction of an iodomethyl radical with $\mathrm{O}_{2}$, triggering significant research activities to study the kinetics of CIs with important tropospheric species, such as $\mathrm{SO}_{2}$, water, and water dimer, ${ }^{24-28}$ to determine $\bullet \mathrm{OH}$ production from $\mathrm{CI}$ unimolecular decomposition, ${ }^{29-31}$ and to develop new methods for their direct measurement ${ }^{32,33}$ and theoretical studies. ${ }^{34-38}$

Ozonolysis of alkenes is highly exoergic and produces a plethora of compounds that scavenge CIs, like the carbonyl species produced in a 1:1 ratio at the initial stage of the ozonolysis, making the observation of CIs very difficult. ${ }^{5,33}$ The advent of a new method for synthesizing CIs from the photolysis of diiodoalkanes, producing $\alpha$-iodoalkyl radicals that produce CIs from subsequent reaction with $\mathrm{O}_{2}$, opened up a series of new studies for direct kinetic measurements. ${ }^{24}$ Direct kinetic measurements of the reaction between formaldehyde oxide $\left(\mathrm{CH}_{2} \mathrm{OO}\right)$ and $\mathrm{SO}_{2}, \mathrm{NO}_{2}, \mathrm{NO}$, and $\mathrm{H}_{2} \mathrm{O}$ have been performed using synchrotron photoionization mass spectrometry (PIMS). ${ }^{24}$ Later on, the same technique led to the discovery of the conformer-dependent reactivity of the syn- and anti-acetaldehyde oxides, ${ }^{27}$ capable of distinguishing the two conformers from the difference in ionization energy. Direct detection of formaldehyde oxide in near-UV cavity ring down spectroscopy ${ }^{28}$ has proven to be a valuable method for direct kinetic studies, together with UV-vis spectroscopy ${ }^{25,26,39}$ and IR spectroscopy. ${ }^{32}$ The latter was used additionally for direct detection of the large $\beta$-pinene Criegee from ozonolysis reaction, and it is potentially applicable to different CIs. ${ }^{33}$

In the present study, we report on the development of a novel method to detect CIs from terpenes and other large alkenes in the gas phase by reaction and stabilization with spin traps, molecules widely applied for detection of free radicals in solutions with electron paramagnetic resonance, ${ }^{40-45}$ and quantification with proton-transfer reaction mass spectrometry. The method proposed here is suitable for online quantification of CIs in the gas phase and allows for the unambiguous identification of CI-spin trap adducts in complex organic mixtures. This technique will therefore provide the long needed tools to study CI reactions and kinetics under atmospherically relevant conditions.

\section{MATERIALS AND METHODS}

2.1. Reagents. For bulk and gas-phase experiments $\alpha$-pinene (98\% $( \pm)-\alpha$-pinene, Aldrich) and oleic acid ( $\geq 99 \%$, GC grade, SigmaAldrich) were reacted with ozone produced by a UV lamp (185/254 $\mathrm{nm}$, Appleton Woods). The spin traps 5,5-dimethyl-pyrroline $N$-oxide (DMPO) ( $\geq 97 \%$, GC grade, Sigma) and $N$-tert-butyl- $\alpha$-phenylnitrone (PBN) ( $\geq 98 \%$, GC grade, Sigma) were used in this study to capture and stabilize the Criegee intermediates. Acetonitrile ( $>99.9 \%$ Optima LC/MS grade, Fisher Chemical) was used as the solvent for bulk reaction. Water with $0.1 \%$ formic acid (Optima LC/MS grade, Fisher Chemical) and methanol (>99.9\% Optima LC/MS grade, Fisher Chemical) were used for HPLC separation, and deuterated acetonitrile (acetonitrile D3 $\geq 99.80 \%$, NMR solvent, Euriso-Top) was used for NMR measurements.

2.2. Bulk Ozonolysis. The olefinic precursor $(\alpha$-pinene or oleic acid) and the spin trap (DMPO or PBN) were dissolved in $100 \mathrm{~mL}$ of acetonitrile (solvent used in previous ozonolysis studies) ${ }^{46}$ at room temperature $\left(16-18{ }^{\circ} \mathrm{C}\right)$ at a concentration of $1 \mathrm{mM}$ for the olefinic compound and $2 \mathrm{mM}$ for the spin trap. The solution was placed in an ice bath for the reaction, as the spin trap adducts are more stable at lower temperatures and to minimize solvent evaporation. ${ }^{47}$

The UV lamp used for ozone production was switched on and equilibrated for at least $20 \mathrm{~min}$ with a flow of synthetic air (Zero grade, $\mathrm{BOC}$ ) at $0.3 \mathrm{~L} / \mathrm{min}$ before the start of the reaction. Subsequently, ozone was bubbled at $0.3 \mathrm{~L} / \mathrm{min}$ through the solution via a Teflon tube connected to a Pasteur pipet tip for $1 \mathrm{~h}$ (concentration of 600 $\mathrm{ppm}$ ozone in air). Flow rate was controlled with a mass flow controller (20-2000 $\mathrm{cm}^{3} / \mathrm{min}$ MKS 1179A Mass-Flo controller). Throughout the reaction, the reaction flask was covered completely with aluminum foil to prevent photolysis and closed with parafilm to minimize evaporation and keep ozone concentrations in solutions as close as possible to saturation. Ozone concentration in solution was $1.3 \pm 0.7 \mathrm{mM}$ on average as measured by iodometric titration. ${ }^{48,49}$

Control experiments of ozonolysis of only the spin traps (DMPO + $\mathrm{O}_{3}$ and $\left.\mathrm{PBN}+\mathrm{O}_{3}\right)$ or the olefinic precursors $\left(\alpha\right.$-pinene $+\mathrm{O}_{3}$, and oleic acid $+\mathrm{O}_{3}$ ) were also done under the same experimental conditions. All solutions were analyzed with electrospray ionization high-resolution mass spectrometry (ESI-HRMS), electron paramagnetic resonance (EPR), and nuclear magnetic resonance (NMR), following the procedures described in the following sections.

A strict control of reagent concentrations seems necessary to ensure efficient production of CI-spin trap adducts, including stabilization of ozone output from the UV lamp prior to the start of the reactions. As the spin trap also reacts with ozone, the starting concentrations of reagents and reaction times have to be carefully optimized to ensure efficient CI-spin trap adduct formation. Traces of water dissolved in solution do not seem to affect the efficiency of the reaction. Tests performed with up to $1 \%$ of water in acetonitrile showed no significant decrease of the CI-spin trap signals in direct infusion ESI-HRMS.

2.2.1. ESI-HRMS and HPLC-ESI-HRMS Analyses. The reaction mixtures were analyzed with direct infusion in ESI in positive ionization (flow rate $5 \mu \mathrm{L} / \mathrm{min}$, spray voltage $3.0 \mathrm{kV}$, transfer capillary temperature $275{ }^{\circ} \mathrm{C}$, sheath flow $12 \mathrm{~L} / \mathrm{min}$, S-Lens RF level 60\%) coupled to a high-resolution mass spectrometer (LTQ Velos Orbitrap, Thermo Scientific, Bremen, Germany) with a resolution of 100000 at $\mathrm{m} / \mathrm{z} 400$ and a typical mass accuracy within $\pm 2 \mathrm{ppm}$. Data were acquired in full scan in the $m / z$ range $100-600$ and in MS/MS with a collision-induced dissociation (CID) energy of 30 (normalized collision energy). The instrument was calibrated routinely with a Pierce LTQ Velos ESI positive ion calibration solution (Thermo Scientific).

The $\alpha$-pinene CI adducts with DMPO and PBN were analyzed also with HPLC-HRMS using an Accela system HPLC (Thermo Scientific, San Jose, USA) coupled with a LTQ Velos Orbitrap. A T3 Atlantis C18 column $(3 \mu \mathrm{m} ; 2.1 \times 150 \mathrm{~mm}$; Waters, Milford, USA $)$ was used for chromatographic separation. The injection volume was $50 \mu \mathrm{L}$. The mobile phases were (A) water with $0.1 \%$ formic acid and (B) methanol. Separation was done with two different elution programs detailed in section S1.1 in the Supporting Information. 
2.2.2. EPR Analysis. Samples were kept in dry ice overnight before analysis. Under these conditions, no significant degradation of CIDMPO adducts occurred as shown by ESI-HRMS analysis. Prior to EPR analysis, solutions were transferred into quartz tubes (ID $=3$ $\mathrm{mm}$ ) and subsequently deoxygenated. The ESR spectra were obtained by a Bruker ECS spectrometer operating at X-band equipped with a TMH resonator. Typical acquisition conditions were: microwave power $6 \mathrm{~mW}$, acquisition time $40 \mathrm{~ms} /$ point, modulation amplitude 0.3 $\mathrm{G}(0.03 \mathrm{mT})$, and number of scans 10 . The spectra were fitted with the standard software PEST package from NIEHS. ${ }^{50}$

2.2.3. NMR Analysis. Solvent was evaporated from $100 \mathrm{~mL}$ of sample solution to $\sim 1 \mathrm{~mL}$ under a gentle flow of $\mathrm{N}_{2}$. The Criegee-spin trap adduct was separated with HPLC using the methods described in Section S1.2. Fractions containing the separated adduct have been collected (4 times, $50 \mu \mathrm{L}$ of sample injected in HPLC), combined, evaporated to dryness, and recovered with $1 \mathrm{~mL}$ of deuterated acetonitrile.

Direct analysis of the reaction mixture without prior HPLC separation resulted in a NMR spectrum dominated by signals from unreacted reagents and secondary products which made the identification of key signatures from the CI-DMPO adducts difficult. HPLC-ESI-HRMS has therefore been used to isolate the $\alpha$-pinene CIDMPO adducts (Figure S4), however, probably due to the volatility of the adducts, it was not possible to concentrate the solution enough for NMR detection. For this reason, NMR has been conducted on the CIPBN adducts only (HPLC-ESI-HRMS in Figure S5). PBN is nonvolatile, but has the same nitrone functional group as DMPO, and is expected to react in the same way as DMPO as supported by ESI-HRMS analysis (Figure S2).

The NMR spectra were acquired on a $500 \mathrm{MHz}$ Bruker Avance III HD, with Dual Cryoprobe (carbon observe). The software Topspin 3.2 was used to acquire and Topspin $3.5 p 15$ to process the data. Full characterization including ${ }^{1} \mathrm{H},{ }^{13} \mathrm{C}$, heteronuclear multiple-bond correlation (HMBC), heteronuclear single quantum coherence (HSQC), and homonuclear correlation spectroscopy (COSY) was conducted to confirm molecular structures. Acquisition and data processing details are reported in Section S3.1.

2.3. DFT Calculations. Geometry optimizations and energy calculations have been carried out in the DFT framework with the TURBOMOLE 6.4 suite of programs ${ }^{51}$ by using the $B P 86^{52,53}$ and $\mathrm{B}^{2} \mathrm{LYP}^{54-56}$ functionals, in conjunction with a valence triple- $\zeta$ basis set with polarization functions on all atoms (TZVP). ${ }^{57}$ For the BP86 functional, the resolution-of-the-identity (RI) technique is applied. ${ }^{58}$ As the geometries and the energy differences calculated by the two functionals are very similar, in the Section 3.2 only the BP86 results will be discussed (see Table S3 for the comparison of the BP86 and B3LYP results).

Stationary points of the energy hypersurface have been located by means of energy gradient techniques, and full vibrational analysis has been carried out to further characterize each stationary point.

The optimization of transition-state structures has been carried out according to a procedure based on a pseudo Newton-Raphson method. The search of the transition-state structure is carried out using an eigenvector-following algorithm: The eigenvectors in the Hessian are sorted in ascending order, the first one being that associated with the negative eigenvalue. After the first step, the search is performed by choosing the critical eigenvector with a maximum overlap criterion, which is based on the dot product with the eigenvector followed at the previous step. Finally, the analytical Hessian matrix is calculated to carry out the vibrational analysis of the stationary point.

Free energy $(G)$ values have been obtained from the electronic SCF energy considering three contributions to the total partition function $(Q)$, namely $q_{\text {translational }}, q_{\text {rotational }}, q_{\text {vibrational }}$, under the assumption that $Q$ may be written as the product of such terms. ${ }^{59}$ In order to evaluate enthalpy and entropy contributions, the values of temperature, pressure, and scaling factor for the SCF wavenumbers have been set to $298.15 \mathrm{~K}, 1 \mathrm{bar}$, and 0.9914 , respectively. Rotations have been treated classically, and vibrational modes have been described according to the harmonic approximation. Energies of the van der
Waals complexes have been corrected for the basis set superposition error using the procedure of Boys and Bernardi. ${ }^{60}$

2.4. Gas-Phase Ozonolysis. Ozonolysis of $\alpha$-pinene was chosen as a proof-of-principle model for the detection of CI-spin trap adducts in the gas phase. The ozonolysis reaction was done in a flow tube reactor maintained at ambient temperature $\left(\sim 16^{\circ} \mathrm{C}\right)$ and pressure and dry conditions (relative humidity ca. $<2 \%$ ) shown in Figure 1 . The

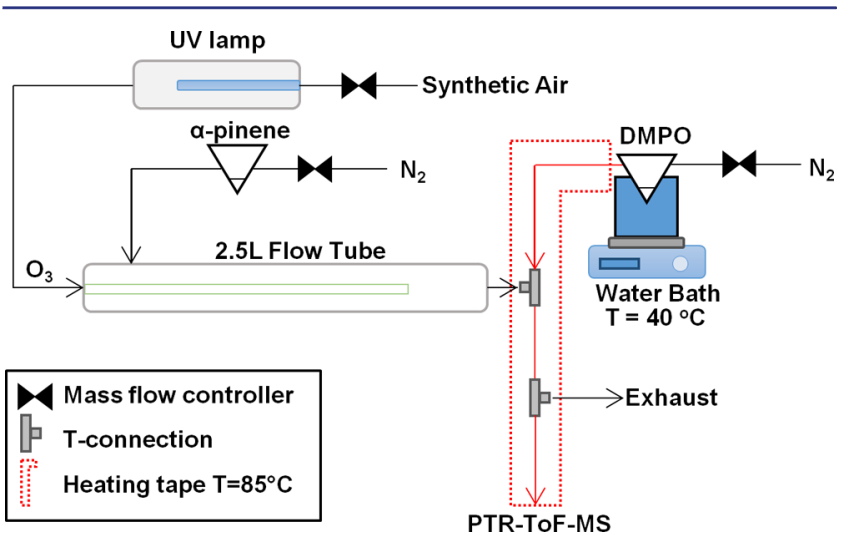

Figure 1. Experimental setup of a $2.5 \mathrm{~L}$ glass flow tube where $\alpha$-pinene reacts with ozone (reaction time $\sim 50 \mathrm{~s}$ ), a mixing point (T-fitting) in which the spin trap is mixed with the sample flow from the flow tube, and a heated PTFE tube in which the spin trap reacts with the carbonyl oxide (CI) before detection and quantification with PTRToF-MS. Additional instruments $\left(\mathrm{O}_{3}\right.$ analyzer and SMPS $)$ were also connected in some experiments sampling from the extra-flow otherwise directed to waste.

experimental setup comprised a $2.5 \mathrm{~L}$ glass flow tube in which $\alpha$ pinene reacts with ozone, a mixing point ( $\mathrm{T}$-fitting) in which the spin trap is mixed with the sample flow from the flow tube, and a heated PTFE tube in which the spin trap reacts with the CI before quantification in the proton-transfer reaction time-of-flight mass spectrometer (PTR-ToF-MS). Additional instruments (ozone analyzer and SMPS) were also connected in some experiments sampling from the exhaust flow (Figure 1). $\alpha$-pinene has been vaporized from a 25 $\mathrm{mL}$ pear-shaped flask filled with $0.5 \mathrm{~mL}$ of pure $\alpha$-pinene with a 175 $\mathrm{cm}^{3} /$ min flow of $\mathrm{N}_{2}$ (oxygen-free nitrogen, BOC) regulated via a 20$2000 \mathrm{~cm}^{3} / \mathrm{min}$ mass flow controller (MKS 1179A Mass-Flo controller). Ozone was produced from a UV lamp (185/254 nm, Appleton Woods) by flowing synthetic air (Zero grade, BOC) at 150 $\mathrm{cm}^{3} / \min \left(20-2000 \mathrm{~cm}^{3} / \mathrm{min}\right.$ MKS 1179 A Mass-Flo controller). The outlet of the flow tube is then mixed into a $\mathrm{T}$ connection (stainlesssteel $1 / 4$ in. $(\sim 6.35 \mathrm{~mm})$ T-fitting, Swagelok) with a $310 \mathrm{~cm}^{3} / \mathrm{min}$ flow (50-5000 $\mathrm{cm}^{3} / \mathrm{min}$ MKS 1179A Mass-Flo controller) of DMPO in $\mathrm{N}_{2}$ (oxygen-free nitrogen, BOC) evaporated from a $25 \mathrm{~mL}$ flask filled with $0.5 \mathrm{~mL}$ of pure DMPO and held in a water bath at $40{ }^{\circ} \mathrm{C}$. Connecting tubes and the $\mathrm{T}$ connection were kept at $85^{\circ} \mathrm{C}$ to avoid condensation of DMPO. The reaction time between the spin trap and the CIs was controlled by varying the length of a $1 / 4 \mathrm{in}$. ( $\mathrm{OD}=6.35$ $\mathrm{mm}, \mathrm{ID}=3.17 \mathrm{~mm}$ ) polytetrafluoroethylene (PTFE) tube kept at 85 ${ }^{\circ} \mathrm{C}$, connecting the mixing point in which DMPO is added with the PTR-ToF-MS (see red line between the two T connections in Figure 1). Ozone was measured using a UV photometric ozone analyzer (Thermo Scientific model 49i), and particle concentration was measured using a TSI scanning mobility particle sizer (SMPS) composed of TSI 3080 electrostatic classifier (X-ray neutralizer and differential mobility analyzer TSI model 3081) and a condensation particle counter (TSI model 3775).

2.4.1. PTR-ToF-MS Measurements. Online gas phase concentrations of $\alpha$-pinene, DMPO, and CI-DMPO adducts were measured using a PTR-ToF-MS 8000 (Ionicon Analytik, Innsbruck, Austria) in the $\mathrm{m} / \mathrm{z}$ range $10-500$, with a time resolution of $10 \mathrm{~s}$ and a mass resolution $m / \Delta m$ of 5000 (full width at half-maximum) at the mass of protonated acetone. Source settings were: drift tube voltage $510 \mathrm{~V}$, 
drift tube pressure $\sim 2.22 \mathrm{mbar}$, and drift tube temperature $90{ }^{\circ} \mathrm{C}$, resulting in an $E / N$ of $\sim 127 \mathrm{Td}\left(1 \mathrm{Td}=10^{-17} \mathrm{~V} \mathrm{~cm}^{2}\right)$. The PTR-ToFMS inlet ( $1 \mathrm{~m}$ long inert peek tube ID $=1 \mathrm{~mm}, \mathrm{OD}=1.59 \mathrm{~mm}$ ) was kept at $100{ }^{\circ} \mathrm{C}$, and the sampling flow rate was $100 \mathrm{~cm}^{3} / \mathrm{min}$. Data analysis was conducted using PTR-MS Viewer 3.1 (Ionicon Analytik). The concentration of $\alpha$-pinene was estimated on the basis of the rate constant $\left(k=2.44 \times 10^{-9} \mathrm{~cm}^{3}\right.$ molecule $\left.\mathrm{e}^{-1} \mathrm{~s}^{-1}\right)$ of the proton-transfer reaction $^{61}$ considering both the protonated molecular ion $(\mathrm{m} / \mathrm{z}$ $137.133)$ and its main fragment $(m / z 81.070)$. For DMPO and the CIDMPO adducts, the rate constant is unknown and therefore a default rate constant $(k)$ of $2 \times 10^{-9} \mathrm{~cm}^{3}$ molecule $\mathrm{e}^{-1} \mathrm{~s}^{-1}$ was used, and only the protonated molecular ion was considered for quantification. DMPO and $\alpha$-pinene signals are often in saturation during the experiments, and therefore the corresponding ${ }^{13} \mathrm{C}$ isotopes were used for quantification.

\section{RESULTS AND DISCUSSION}

3.1. Characterization of Cl-Spin Trap Adducts in ESIHRMS, EPR, and NMR. The acetonitrile solution in which $\alpha$ pinene has been ozonolysed for $1 \mathrm{~h}$ in the presence of DMPO was analyzed with ESI-HRMS, EPR, and NMR.

Ozonolysis of $\alpha$-pinene produces two CIs. Depending on ring opening of the primary ozonide, either a carbonyl oxide with a terminal ketone (Figure $4 a$ ) or a carbonyl oxide with a terminal aldehyde (Figure $4 \mathrm{~b}$ ) can be produced, hereafter named " $\mathrm{CI}_{\mathrm{K}}$ " and " $\mathrm{CI}_{\mathrm{A}}$ ". ESI-HRMS analysis shows the formation of a 1:1 adduct between the spin trap DMPO and the two Criegee intermediates (both at the same mass, $\mathrm{m} / z$ 298.2013, $\mathrm{C}_{16} \mathrm{H}_{28} \mathrm{NO}_{4}^{+}$) from $\alpha$-pinene ozonolysis (Figure 2). The high intensity of the peak from the CI-DMPO adducts and the low intensity of peaks associated with common oxidation

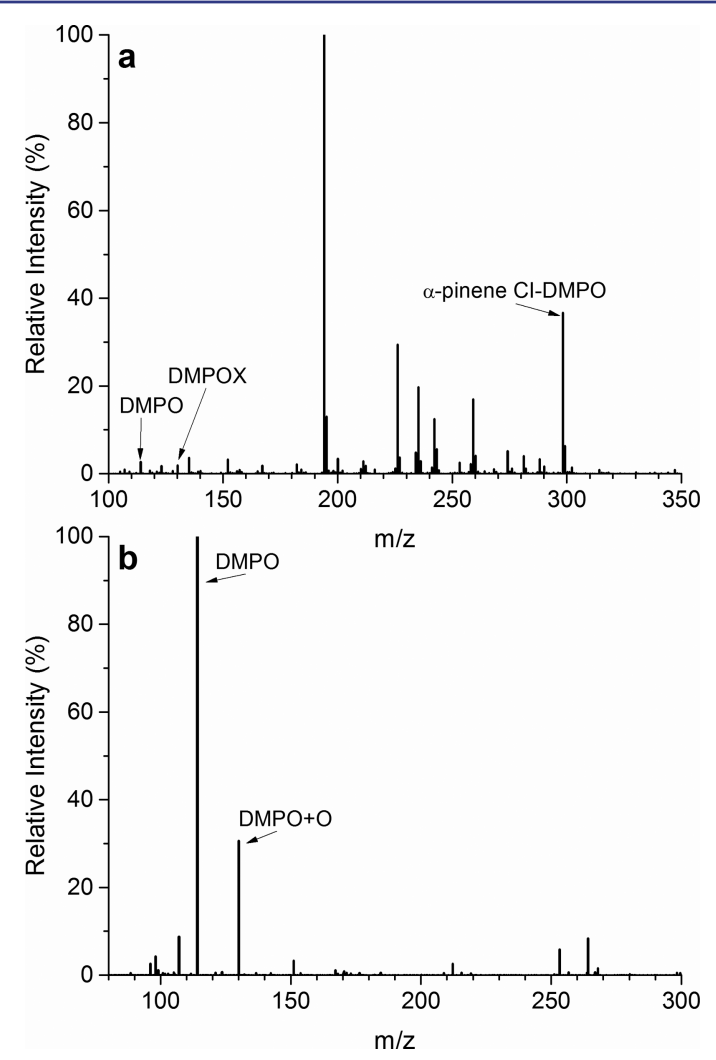

Figure 2. Characterization of CI-DMPO adducts in (a) ESI-HRMS in full scan showing the formation of a 1:1 adduct between the two $\alpha$ pinene CIs and the DMPO at $m / z 298.2013$ (the two CIs have the same mass), and (b) MS/MS analysis of the CI-DMPO adducts. products from the ozonolysis of $\alpha$-pinene imply good efficiency of the trapping reaction. MS/MS analysis on the CI-DMPO adducts shows the presence of two main fragments corresponding to the DMPO and the DMPO with one additional oxygen atom (Figure $2 b$ ), suggesting that the oxygen centered radical of the Criegee intermediates attacks the nitrone group of the DMPO at the carbon atom. Control experiments of ozonolysis of $\alpha$-pinene and ozonolysis of DMPO showed no formation of the peak associated with the CI-DMPO adducts (Figure S1). Similar results have been obtained using the spin trap PBN and for the ozonolysis of oleic acid (Figure S2 and S3). In all cases, we observe all expected $\alpha$-pinene CI-PBN adducts (the two adducts have the same mass) and oleic acid CI-DMPO adducts (two adducts with two different masses).

The room-temperature EPR spectra in acetonitrile of the $\alpha$ pinene CI-DMPO sample and DMPO $+\mathrm{O}_{3}$ control sample are shown in Figure 3. Both spectra are characterized by the

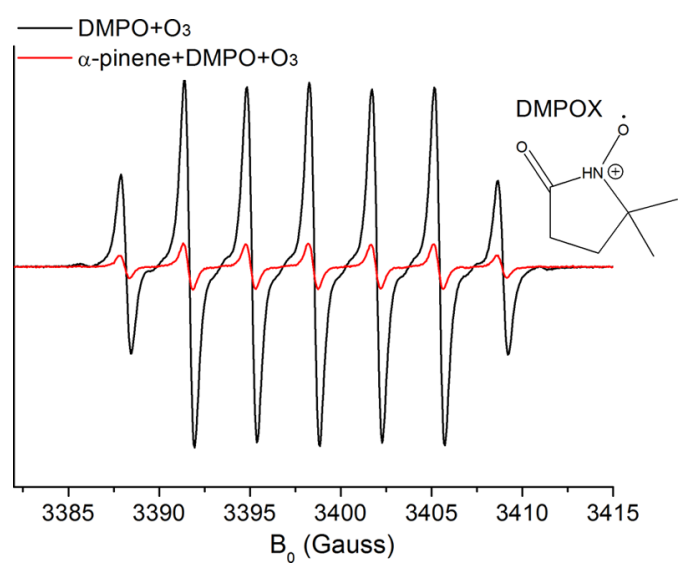

Figure 3. EPR spectrum at room temperature in acetonitrile showing the species DMPOX (see molecular structure) formed from oxidation of DMPO, but no biradical adducts formed.

presence of a single species with hyperfine interaction with a nitrogen $\left(a_{0}=6.9 \mathrm{G}\right)$ and two equivalent protons $\left(a_{0}=3.5 \mathrm{G}\right)$. The hyperfine splitting of the nitrogen is unusually low compared with typical spin adducts of DMPO $(\sim 15 \mathrm{G}) .^{62}$ The spectra are instead consistent with that reported for 5,5dimethyl-2-pyrrolidone- $N$-oxyl (DMPOX, see structure in Figure 3), a degradation product found under harsh oxidizing conditions, ${ }^{63}$ for which values of $6.27-6.87 \mathrm{G}$ and $3.18-3.65 \mathrm{G}$ for the hyperfine coupling constants of nitrogen and protons in different solvents were found in a previous study. ${ }^{62}$ ESI-HRMS analysis of both the reaction solution (Figure 2) and control experiment (Figure S1) confirms the presence of a peak at $\mathrm{m} / z$ 130 that can be explained with DMPOX after abstraction of $\bullet \mathrm{H}$ from another molecule in the sample mixture (observed mass is shifted at $+1 \mathrm{Da}$ relative to the mass of DMPOX, see Figure 2). Previous studies associated $\mathrm{m} / z 130$ with an adduct between the DMPO and $\bullet \mathrm{OH}^{4,45,64-66}$ which was not observed in EPR in our experiments. When $\alpha$-pinene was present in the reactor, the line shape of the EPR spectrum was unaffected, confirming the presence of the DMPOX species, but at much lower concentration (see Figure 3, red line). No other radical species were observed, and in particular no radical-type spin adducts with $\alpha$-pinene CIs were found. This is consistent with a previous work from Pryor et al., ${ }^{40}$ in which spin traps have been used to study formation of radicals from ozone-olefin reactions 


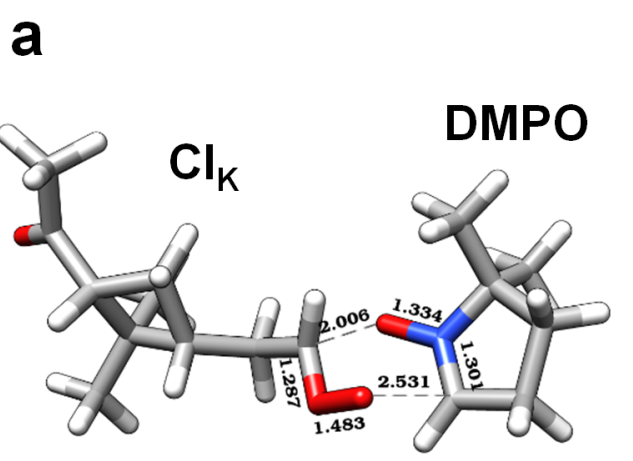

b

TS-CI $_{K}-6 R-R_{\text {trans }}$

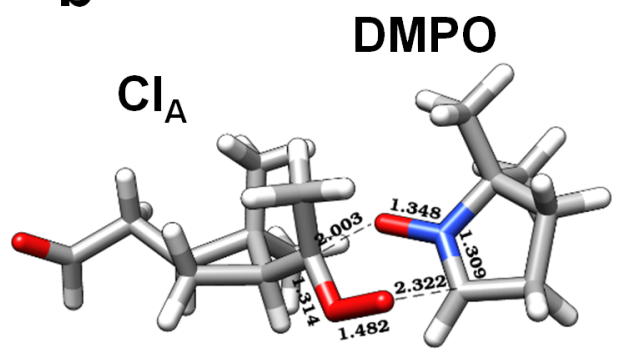

TS-CI $\mathbf{A}^{-6 R-R R_{\text {trans }}}$
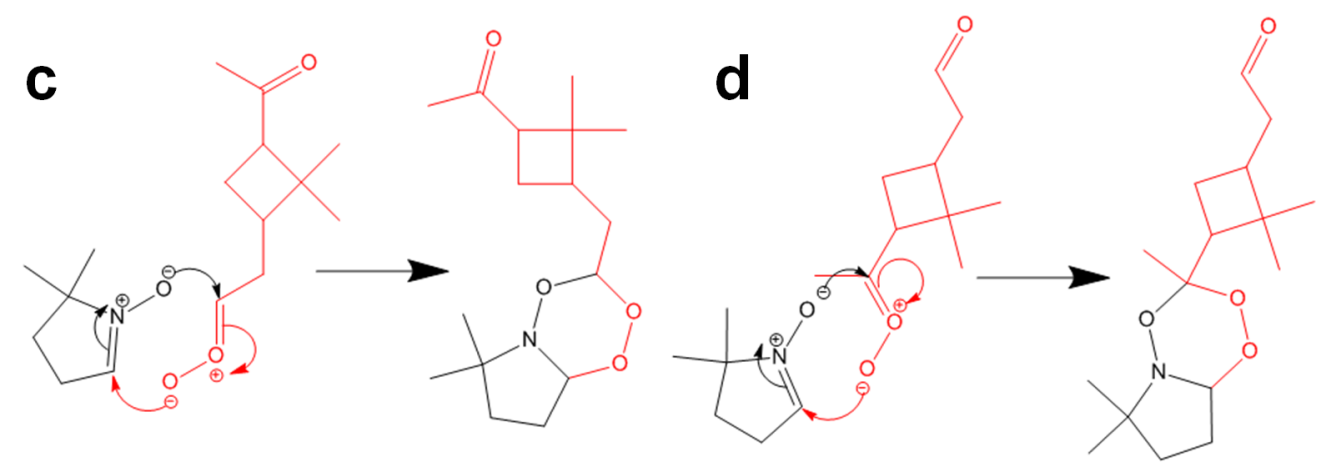

Figure 4. Optimized structures (with selected distances in $\AA$ ) of the transition states for the $\mathrm{CI}_{\mathrm{K}(180)}+\mathrm{DMPO} \rightarrow \mathrm{CI}_{\mathrm{K}}-\mathrm{DMPO}$ reaction $(\mathrm{a})$ and $\mathrm{CI}_{\mathrm{A}(180)}+\mathrm{DMPO} \rightarrow \mathrm{CI}_{\mathrm{A}}-\mathrm{DMPO}$ reaction $(\mathrm{b})$ and proposed mechanism of reaction of cycloaddition of $\mathrm{CI}_{\mathrm{K}}+\mathrm{DMPO} \rightarrow \mathrm{CI}_{\mathrm{K}}-\mathrm{DMPO}(\mathrm{c})$ and $\mathrm{CI}_{\mathrm{A}}+$ $\mathrm{DMPO} \rightarrow \mathrm{CI}_{\mathrm{A}}-\mathrm{DMPO}(\mathrm{d})$.

at $-78{ }^{\circ} \mathrm{C}$ in Freon-11, and no Criegee-spin trap adducts have been observed with EPR.

From the results of the ESI-HRMS and EPR analyses, we hypothesized the formation of a nonradical adduct by cycloaddition of the carbonyl oxides to the nitrone group of the spin traps forming a six-atom heterocycle (Figure 4).

As described in the Materials and Methods section, NMR analyses were performed with the spin trap PBN due to its lower volatility compared to DMPO (proposed reaction mechanism between $\alpha$-pinene CI and PBN are analogous to reaction shown in Figure 4). NMR analysis of the purified CIPBN adducts (see the NMR Analysis section for details on sample preparation and method) confirms the presence and the structure of the $\mathrm{CI}_{\mathrm{K}}-\mathrm{PBN}$ adduct as shown in Figure 5 from the characteristic triplet of the proton of the $-\mathrm{CH}$ between the two oxygen atoms and signal of the proton of the $-\mathrm{CH}$ between the nitrogen and oxygen atoms in the heterocycle, nicely matching the simulation in Table S2. NMR spectra suggest also the presence of the $\mathrm{CI}_{\mathrm{A}}-\mathrm{PBN}$ adduct however at a lower concentration, as observed from the lower intensity of signals in NMR associated with the $\mathrm{CI}_{\mathrm{A}}$-PBN adduct. The presence of the $\mathrm{CI}_{\mathrm{A}}$-PBN adduct can be observed also from the double peak of the proton at $\sim 5.77 \mathrm{ppm}$ (Figure 5). More details on the results of the NMR characterization and full NMR spectra can be found in Section S3.2.

3.2. DFT Calculations. Theoretical DFT calculations were undertaken in order to probe the stability of the proposed CIDMPO adducts and to investigate the mechanism of their formation.

An extensive search on the potential energy surface (PES) of the two CIs generated from the ozonolysis of $\alpha$-pinene, and encompassing the $\mathrm{CI}_{\mathrm{K}}$ and $\mathrm{CI}_{\mathrm{A}}$, was carried out to identify all minimum energy conformations. We found that the two isomers with the lowest energy conformation feature a nearly planar arrangement of the CCOO group with a dihedral angle equal to about $0^{\circ}\left(\mathrm{CI}_{\mathrm{A}(0)}\right.$ and $\mathrm{CI}_{\mathrm{K}(0)}$; see Figure $\left.\mathrm{S} 17\right)$, in agreement with previous calculations. ${ }^{67,68} \mathrm{CI}_{\mathrm{A}}$ in this lowest energy conformation is more stable than $\mathrm{CI}_{\mathrm{K}}$ by about $1.5 \mathrm{kcal} /$ mol, which closely matches the value of $2.6 \mathrm{kcal} / \mathrm{mol}$ calculated by Zhang et al. ${ }^{68}$ using the $\operatorname{CCSD}(\mathrm{T}) / 6-31 \mathrm{G}(\mathrm{d})+\mathrm{CF}$ level of theory. A second relevant conformation of the two $\mathrm{CI}$ isomers is characterized by the dihedral angle of the $\mathrm{CCOO}$ group equal to about $180^{\circ}\left(\mathrm{CI}_{\mathrm{A}(180)}\right.$ and $\mathrm{CI}_{\mathrm{K}(180)}$; see Figure $\left.\mathrm{S} 17\right)$. The two CIs in this conformation are slightly less stable than $\mathrm{CI}_{\mathrm{A}(0)}$ and $\mathrm{CI}_{\mathrm{K}(0)}$ (about $0.2 \mathrm{kcal} / \mathrm{mol}$ for $\mathrm{CI}_{\mathrm{A}(180)}$ and $2 \mathrm{kcal} / \mathrm{mol}$ for $\left.\mathrm{CI}_{\mathrm{K}(180)}\right)$, and $\mathrm{CI}_{\mathrm{A}(180)}$ is more stable than $\mathrm{CI}_{\mathrm{K}(180)}$ by $3.5 \mathrm{kcal} /$ mol.

The cycloaddition of the two CIs to the spin-trap DMPO can occur through the attack of the carbon atom of the CI to either the nitrogen or the oxygen atoms of the DMPO nitrone group, leading to the formation of a five-membered or a six-membered ring, respectively. A recent IR spectrum of the parent CI $\mathrm{CH}_{2} \mathrm{OO}^{32}$ as well as earlier theoretical calculations ${ }^{6}$ are more consistent with a zwitterion (1,3 dipole) rather than a diradical nature of CIs. Therefore, the two reactions described above can be considered as 1,3 dipolar cycloaddition reactions. It is important to note that the reaction of the two CIs with the spin-trap DMPO can generate four stereoisomers, as the ring closure leads to the formation of two stereogenic centers, one at the carbon atom of the CI and the other at the carbon atom of the nitrone group. These four stereoisomers (neglecting the chirality of the CI) consist of the two RR/SS and RS/SR pairs of enantiomers. In addition, the six-membered ring adducts can adopt two conformations which differ for the relative cis/trans 


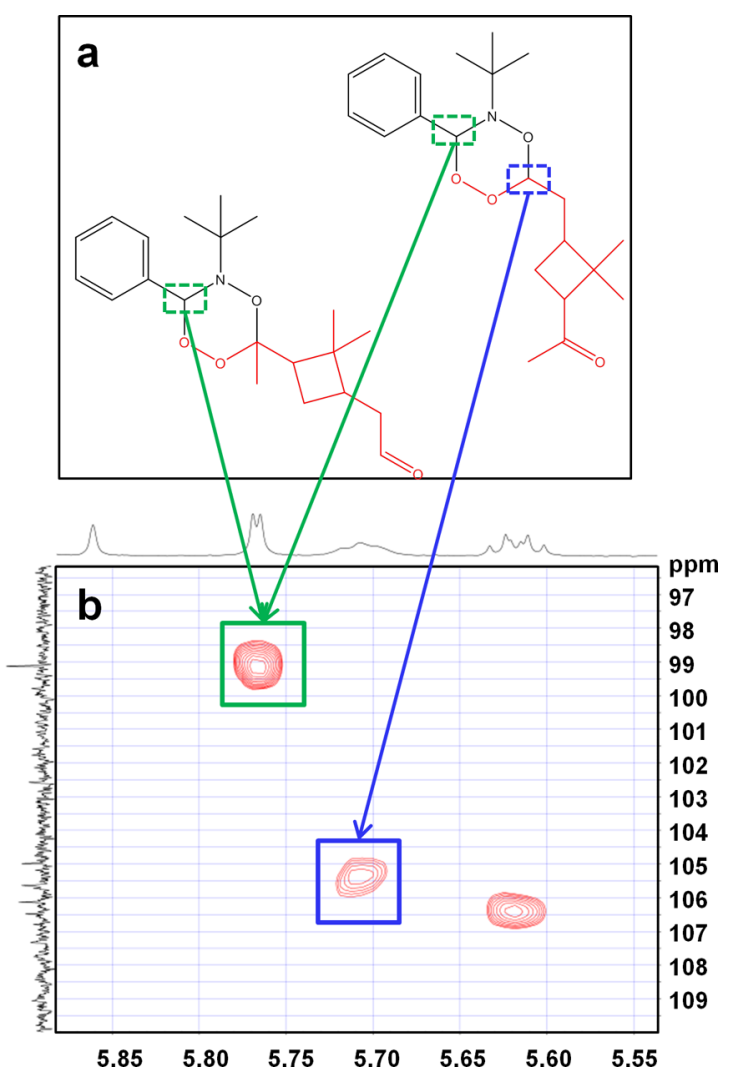

Figure 5. Proposed structures of the two $\alpha$-pinene CI-PBN adducts (a) and HSQC-NMR spectrum (b) showing the correlation between the two protons in the six-atom heterocycle and their carbon atoms of the $\alpha$-pinene $\mathrm{CI}_{\mathrm{K}}-\mathrm{PBN}$ adduct and the correlation between the proton in the six-atom heterocycle and its carbon atoms of the $\alpha$-pinene $\mathrm{CI}_{\mathrm{A}^{-}}$ PBN adduct.

orientation of the nitrogen lone pair and the hydrogen of the adjacent carbon atom (like in the cis and trans decaline). It is important to note that the trans conformation is originated from the CIs in the " $180^{\circ}$ ” conformation $\left(\mathrm{CI}_{\mathrm{A}(180)} / \mathrm{CI}_{\mathrm{K}(180)}\right)$, whereas the cis conformation is generated when the reactant CIs are in the " $0^{\circ}$ " conformation $\left(\mathrm{CI}_{\mathrm{A}(0)} / \mathrm{CI}_{\mathrm{K}(0)}\right)$. In the fivemembered ring adducts, due to the stereospecific mechanism of the addition reaction, which occurs with retention of configuration, only the product with the cis orientation of the terminal oxygen bounded to nitrogen and the adjacent carbon atom can be formed.

The relative stabilities of all of the isomers investigated and the free energy of the $\mathrm{CI}+\mathrm{DMPO} \rightarrow \mathrm{CI}-\mathrm{DMPO}$ reaction leading to their formation are reported in Table S4. Notably, the adducts formed by the attack of CI to the oxygen atom of the nitrone group of DMPO with closure of the six-membered ring are significantly more stable than the adducts in which the attack occurs to the nitrogen atom to give the five-membered ring. The relative stabilities are also strongly dependent on the nature of the $\mathrm{CI}$, as the adducts formed by the addition of the $\mathrm{CI}_{\mathrm{K}}$ intermediate are more than $9 \mathrm{kcal} / \mathrm{mol}$ lower in energy than those formed by the addition of $\mathrm{CI}_{\mathrm{A}}$. In the case of the sixmembered ring adducts, the two pairs of diasteroisomers are almost isoenergetic with the RR/SS stereoisomers, slightly more stable than RS/SR ones, whereas for the five-membered ring adducts the difference in stability is larger, with the RR/SS stereoisomers more than $6 \mathrm{kcal} / \mathrm{mol}$ lower in energy than the
RS/SR ones. The geometry of the most stable stereoisomer for each of the four adducts investigated is shown in Figure S18.

Calculated free energy of reactions $\left(\Delta G_{\mathrm{r}}\right)$ shows that addition of $\mathrm{CI}_{\mathrm{K}}$ to DMPO with formation of the six-membered ring adduct is strongly exoergonic with the $\Delta G_{\mathrm{r}}$ value, referred to the formation of the most stable stereoisomer, as low as -32 $\mathrm{kcal} / \mathrm{mol}$. The $\Delta G_{\mathrm{r}}$ calculated for the corresponding most stable adduct obtained by the reaction of $\mathrm{CI}_{\mathrm{A}}$ is equal to about $-19 \mathrm{kcal} / \mathrm{mol}$. The reaction of $\mathrm{CI}_{\mathrm{K}}$ with $\mathrm{DMPO}$ to give the five-membered ring adduct is still exoergonic by about -13 $\mathrm{kcal} / \mathrm{mol}$, whereas the reaction with $\mathrm{CI}_{\mathrm{A}}$ is slightly endoergonic (see Table S4).

The calculated activation free energies for the cyclization reactions can help further in discriminating among the different mechanisms. The lowest energy barriers were calculated starting from the CIs reactants in the " $180^{\circ}$ " conformation $\left(\mathrm{CI}_{\mathrm{A}(180)} / \mathrm{CI}_{\mathrm{K}(180)}\right)$ and, in the case of the six-membered ring adducts, leading to the trans conformers. The cyclization reactions are preceded by the formation of prereactive van der Waals complexes between CIs and DMPO, which, for $\mathrm{CI}_{\mathrm{K}(180)}$ $\left(\mathrm{vdw}-\mathrm{CI}_{\mathrm{K}(180)}\right)$ and $\mathrm{CI}_{\mathrm{A}(180)}\left(\mathrm{vdw}-\mathrm{CI}_{\mathrm{A}(180)}\right)$, are about 3 and 2 $\mathrm{kcal} / \mathrm{mol}$ more stable than the separated reactants, respectively. The $\Delta G^{\#}$ calculated for the addition of $\mathrm{CI}_{\mathrm{K}(180)}$ to DMPO to form the six-membered ring adduct is as small as $2.3 \mathrm{kcal} / \mathrm{mol}$ with respect to the separated reactants, indicating that the reaction is characterized by a very small energy barrier. On the other hand, the $\Delta G^{\#}$ calculated for the formation of sixmembered ring adduct from $\mathrm{CI}_{\mathrm{A}(180)}$ is higher in energy and equal to about $12 \mathrm{kcal} / \mathrm{mol}$. The $\Delta G^{\#}$ calculated for the reaction of CIs in the " 0 " conformation $\left(\mathrm{CI}_{\mathrm{A}(0)} / \mathrm{CI}_{\mathrm{K}(0)}\right)$ is slightly larger than that calculated considering the $\mathrm{CI}_{\mathrm{K}(180)}$ and $\mathrm{CI}_{\mathrm{A}(180)}$ conformers as reactants and equal to about 8 and 18 $\mathrm{kcal} / \mathrm{mol}$ for $\mathrm{CI}_{\mathrm{K}(0)}$ and $\mathrm{CI}_{\mathrm{A}(0)}$, respectively. Notably, the activation free energies for the formation of the two adducts featuring a five-membered ring are significantly higher and equal to about 36 and $49 \mathrm{kcal} \mathrm{mol}^{-1}$ for the reaction occurring with $\mathrm{CI}_{\mathrm{K}(180)}$ and $\mathrm{CI}_{\mathrm{A}(180)}$, respectively. As shown in Figure 4, the transition state of the cycloaddition reaction to the sixmembered ring adduct is asymmetric with the carbon atom of $\mathrm{CI}$ approaching the oxygen atom of DMPO at a distance of about $2.0 \AA$, and the $\mathrm{O}_{\mathrm{CI}}-\mathrm{C}_{\mathrm{DMPO}}$ distance is significantly longer ( $\sim 2.3$ and $\sim 2.5 \AA$ for $\mathrm{CI}_{\mathrm{K}}$ and $\mathrm{CI}_{\mathrm{K}}$, respectively). The transition state for the five-membered ring adduct is reported in Figure S19.

The simplified orbital diagram reported in Figure S20 can explain the mechanism of the addition of the CI to the DMPO to give the six-membered ring adduct. Indeed, the HOMO of DMPO is a $\pi$-orbital of the $\mathrm{C}=\mathrm{N}-\mathrm{O}$ framework, with a significant contribution on the oxygen atom, which can interact with the LUMO of CI mainly localized on the carbon atom. The formation of the $\mathrm{C}_{\mathrm{CI}} \mathrm{O}_{\mathrm{DMPO}}$ bond decreases the electron density on the carbon atom of DMPO which can then interact with the HOMO of $\mathrm{CI}$, mainly localized on terminal oxygen atom. Considering this scheme, the ring closure at the nitrogen atom leading to formation of the five-membered ring adduct should first provide a significant structural rearrangement of DMPO with the oxygen atom moving outside the $\mathrm{C}=\mathrm{N}-\mathrm{O}$ plane and therefore accounting for the very large activation free energy of this process.

Figure 6 summarizes the results presented above, showing the lowest reaction energy profiles for the formation of the CIDMPO adducts. It is evident that the more favorable pathway corresponds to the formation of the six-membered ring adduct 


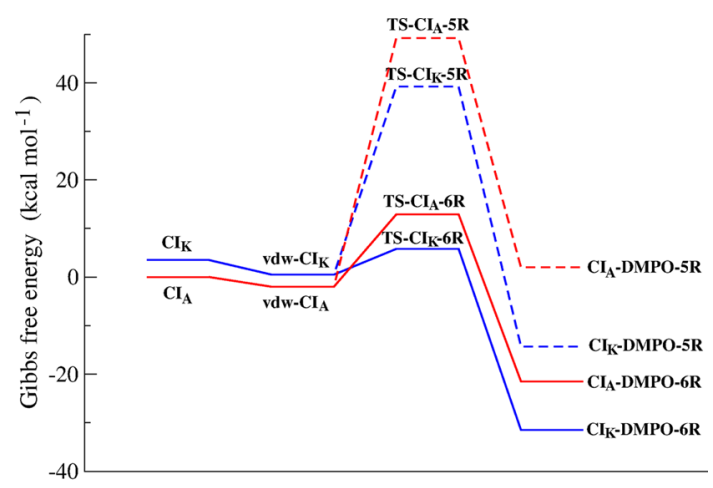

Reaction coordinate

Figure 6. Reaction energy profiles of the $\mathrm{CI}_{\mathrm{K}}+\mathrm{DMPO} \rightarrow \mathrm{CI}_{\mathrm{K}}$-DMPO (in red) and $\mathrm{CI}_{\mathrm{A}}+\mathrm{DMPO} \rightarrow \mathrm{CI}_{\mathrm{A}}-\mathrm{DMPO}$ (in blue) reactions, calculated considering the lowest reaction energy profile for the formation of each adduct. Pathways leading to the five-membered ring adducts are drawn with dashed lines.

from $\mathrm{CI}_{\mathrm{K}}$. The very low-energy barrier and the large stability of the product suggest that the reaction between $\mathrm{CI}_{\mathrm{K}}$ and DMPO is very fast and competitive with other reactions of the very reactive CIs.

3.3. Quantification of Criegee Intermediates in the Gas Phase. 3.3.1. Optimization of the Experimental Setup. Optimized concentrations of $\alpha$-pinene, DMPO, and $\mathrm{O}_{3}$ of 340, 150, and $290 \mathrm{ppm}$, respectively (achieved with the conditions described in Gas-Phase Ozonolysis section after optimization as described in Section S2.2) were used to detect the CI-DMPO adduct appreciably above quantification limits with $\alpha$-pineneozone reaction time of $\sim 50 \mathrm{~s}$. This reaction time represents an upper limit, as it assumes instantaneous mixing between $\alpha$ pinene and ozone. Using very short reaction times of only a few seconds would lead to more ozone left over at the end of the flow tube that can react with DMPO, which would decrease the efficiency of the spin trapping reaction. The high concentrations of reagents cause the primary ion $\left[\mathrm{H}_{3} \mathrm{O}\right]^{+}$to decrease, which inherently affects measurement accuracy especially for compounds like CI-DMPO adducts, for which there are no calibration standards currently available. The concentrations of $\alpha$-pinene and DMPO in our experimental conditions were estimated in dilution experiments, where the total flow was diluted by a factor of 10 (from $\sim 600 \mathrm{~cm}^{3} / \mathrm{min}$ to $\sim 6 \mathrm{~L} / \mathrm{min}$ ), and the ${ }^{13} \mathrm{C}$ isotopes of the molecular ions have been used to estimate concentrations of the parent compound. This was necessary because the parent ions were still in saturation even after a 10X dilution. The measurement uncertainty in our experimental conditions was estimated by comparing measured concentrations of the ${ }^{13} \mathrm{C}$ isotopes of $\alpha$-pinene and DMPO under normal operating conditions (i.e., where signals were not in saturation) and under high concentration conditions used in our experiments. In the latter case, measured concentrations were underestimated by a factor of 10 , but their concentrations being in the ppm range may not be within the linear response range of the PTR-ToF-MS. For this reason, concentration of other VOCs in our system may not be underestimated by the same extent. According to these reference experiments, CIDMPO concentrations reported here may be underestimated by about a factor of 10 . Additionally, ozonolysis of $\alpha$-pinene results in substantial secondary organic aerosol formation $(\sim 10$ $\mathrm{mg} / \mathrm{m}^{3}$ in our experimental conditions) as a result of the partitioning of semivolatile products into the particle phase, which can further complicate the chemistry in this reaction system.

The temperature of the flow tube where the $\alpha$-pinene ozonolysis took place was varied by changing the lab temperature between 16 and $20{ }^{\circ} \mathrm{C}$. At $16{ }^{\circ} \mathrm{C}$, higher $\mathrm{CI}$ DMPO adduct concentrations were observed, by about a factor of $\sim 1.5$, compared to $20{ }^{\circ} \mathrm{C}$, probably because at higher temperatures $\mathrm{CIs}$ decompose faster. The temperature of the PTFE tube, where DMPO reacts with $\mathrm{CI}$, was varied from room temperature $\left(\sim 16{ }^{\circ} \mathrm{C}\right)$ up to $95{ }^{\circ} \mathrm{C}$ to minimize losses (i.e., condensation or adsorption) to the walls of DMPO and DMPO adducts. The concentration of the adduct increases with temperatures reaching a plateau around $85{ }^{\circ} \mathrm{C}$. No evidence of degradation of the adduct has been observed (at a reaction time of $1.5 \mathrm{~s}$ ). A working temperature of $85{ }^{\circ} \mathrm{C}$ was chosen, giving higher concentrations of adduct and good repeatability.

The time for the CI-spin trap reaction was optimized by varying the length of a PTFE tube connecting the mixing point with the PTR-ToF-MS inlet (red line between the two T connections in Figure 1) from 0 to $200 \mathrm{~cm}$ (corresponding to a reaction time ranging between 0 and $1.5 \mathrm{~s}(+\sim 0.5 \mathrm{~s}$ in the PTR-MS inlet) with a total flow rate of $635 \mathrm{~cm}^{3} / \mathrm{min}$ ) kept for these tests at $75{ }^{\circ} \mathrm{C}$. The measured amount of the CI-DMPO adducts increases slightly with longer residence time, reaching a plateau at $\sim 1 \mathrm{~s}$ (Figure S6). For this reason, a PTFE tube with length of $200 \mathrm{~cm}$ corresponding to a residence time of $1.5 \mathrm{~s}$ has been chosen.

The temperature of the PTR-ToF-MS inlet and drift tube was adjusted in order to minimize condensation of DMPO and DMPO adducts on the walls (tests of stability of CI-DMPO adducts are described in Section S2.1). Temperature was changed between 60 and $100{ }^{\circ} \mathrm{C}$. The highest and most reproducible MS signals of DMPO and CI-DMPO adduct were obtained with an inlet temperature of $100{ }^{\circ} \mathrm{C}$ and drift tube temperature of $90{ }^{\circ} \mathrm{C}$.

3.3.2. Detection of CI-DMPO Adducts in the Gas Phase and Method Performances. The adduct formed between the spin trap DMPO and the $\alpha$-pinene CIs, with the elemental formula $\mathrm{C}_{16} \mathrm{H}_{28} \mathrm{NO}_{4}{ }^{+}$, was detected by the PTR-ToF-MS at $m$ / $z 298.20$ using the optimized conditions described above. Figure 7 illustrates that CI-DMPO adducts formed in the flow tube reaction system $(\alpha$-pinene-ozone reaction time $\sim 50 \mathrm{~s})$ are stable over time. The CI-DMPO peak was on average $1.6 \mathrm{ppb}$ for the duration of the experiments. An initial increase in CIDMPO concentration observed to $2 \mathrm{ppb}$ at around $25 \mathrm{~min}$ is likely associated with a varying amount of $\mathrm{O}_{3}$ produced from the UV lamp, as it initially warms up over about $20 \mathrm{~min}$ (in which ozone concentration exponentially increases before reaching a plateau), varying the reaction conditions in the flow tube. The concentrations of the CI-DMPO adduct obtained are stable for several hours (Figure 7b) and highly reproducible in this system, with a variation of $\pm 0.5 \mathrm{ppb}$ observed in multiple repeats. The observed concentration of the CI-DMPO is about 5 orders of magnitude lower compared with the initial concentration of the reagents, which were measured at 293, 340, and $150 \mathrm{ppm}$ for $\mathrm{O}_{3}, \alpha$-pinene, and DMPO, respectively, and about 2 orders of magnitude lower than the concentration of the reagents at the steady-state. A simulation run using the MCM model (v 3.3.1) suggests that in the $50 \mathrm{~s}$ reaction time $\left(\alpha\right.$-pinene- $\mathrm{O}_{3}$ reaction time in the flow tube under dry conditions before mixing with the DMPO), the excited $\mathrm{CI}_{\mathrm{A}}$ and $\mathrm{CI}_{\mathrm{K}}$ have already undergone unimolecular 

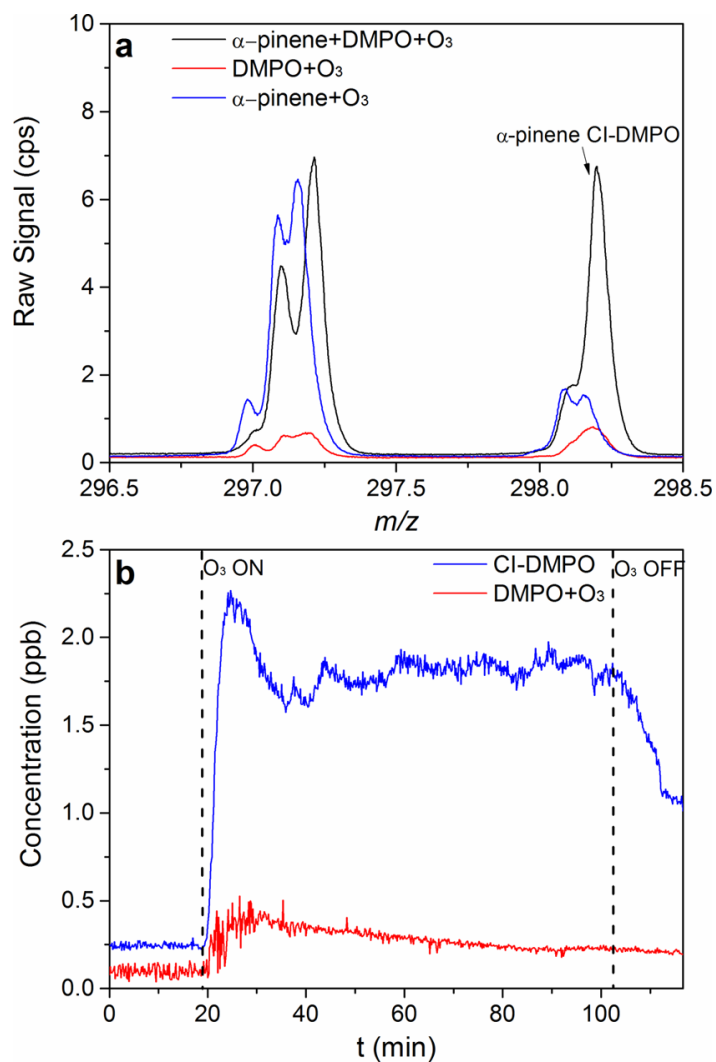

Figure 7. Detection of $\alpha$-pinene CI-DMPO adduct in the gas phase in PTR-ToF-MS. (a) Example of mass spectrum at steady-state showing the peak at $m / z 298.20$, corresponding to the two $\alpha$-pinene CI-DMPO adducts. (b) Time trace of the mass corresponding to the CI-DMPO adduct compared with the control experiment of DMPO ozonolysis (without $\alpha$-pinene). The concentration of CI-DMPO adducts decreases very slowly to zero in about $1.5 \mathrm{~h}$ after the ozone is switched off, probably due to memory effects.

decomposition or isomerization ${ }^{69}$ and/or collisional stabilization. The observed concentration of CI-DMPO of $1.6 \mathrm{ppb}$ is in reasonable agreement to the predicted value of $14.8 \mathrm{ppb}$ of stabilized $\mathrm{CI}_{\mathrm{K}}$ obtained from the MCM model. This suggests that quantification of CI-DMPO with the PTR-ToF-MS could be achieved; however, specific calibration procedures should be developed to improve measurement accuracy considering that the rate of the specific proton-transfer reaction is not known and calibration standards are currently not available. The discrepancy between modeled and experimentally determined concentrations is about an order of magnitude, with higher values estimated by the model. This could be due to both uncertainties in the model and the experiments. In this study we cannot address MCM model uncertainties, but a potential reason for the discrepancy is our assumption that $100 \%$ of the $\mathrm{CI}$ present at the mixing point reacts with DMPO. The reaction rate between CI and DMPO is unknown but likely not all CI reacts with DMPO, which is not taken into account here. This is possibly the major factor explaining the lower concentration determined experimentally and should be addressed in future studies by determining DMPO - CI reaction rate constants experimentally. In addition, a fraction of the CI-DMPO adducts could possibly be lost (adsorbed) on the walls of the transfer line, and poorly defined ionization efficiencies of the CI-DMPO adducts in the PTR-ToF-MS could add to the lower concentrations determined experimentally compared to MCM model results.

Concerning possible interferences in our measurements, three $\alpha$-pinene oxidation products with the same molecular formula as the CIs, i.e., pinonic acid, dioxirane, and vinyl hydroperoxide, are produced in the system. Pinonic acid does not interfere at the mass of CIs-DMPO because it does not react with DMPO, as shown in tests in solution. Dioxirane can react with the spin trap but does not produce a stable adduct, according to the reaction mechanism proposed by Adam et al. ${ }^{70}$ The vinyl hydroperoxides produced from the decomposition of the CIs are produced with a high excess energy and should promptly decompose to produce $\bullet \mathrm{OH}^{71}$ Nevertheless, some stabilization mechanism may increase their lifetime, and the reaction with DMPO may produce an interference, the extent of which has to be assessed in future investigations. The hydroperoxide formed in the reaction of $\alpha$-pinene with $\bullet \mathrm{OH}$, the latter being generated in high yields in the gas phase, has a mass $1 \mathrm{Da}$ larger than that of the CIs and should produce a stable radical adduct with a mass $1 \mathrm{Da}$ larger than that of the CIs-DMPO adducts. There are no available data on the stability of those species in the gas phase, but if this adduct would decompose by losing an $\mathrm{H}$ atom, then this could potentially interfere with the $\mathrm{CI}$ adduct measurement. The closest information we found in the literature about DMPO adduct stabilities are measurements of the DMPO-OH radical with a half-life of ca. $3 \mathrm{~min}$ in water $^{72}$ and in vivo, ${ }^{73}$ which is significantly longer than the residence time of ca. $1.5 \mathrm{~s}$ from the mixing point of DMPO to the PTR-ToF-MS. Therefore, a potential hydroperoxide adduct interference is likely very minor under our experimental conditions. The detection limit for $\alpha$ pinene CI-DMPO adducts is $0.03 \mathrm{ppb}\left(3 \sigma_{\mathrm{bl}}\right.$ method $)$, and the quantification limit is $0.10 \mathrm{ppb}\left(10 \sigma_{\mathrm{bl}}\right.$ method) with a time resolution of $10 \mathrm{~s}$. The CI-DMPO peak partly overlaps with the ${ }^{13} \mathrm{C}$ isotope of a contaminant and $\alpha$-pinene oxidation product at $m / z \sim 297.16\left(\mathrm{C}_{16} \mathrm{H}_{26} \mathrm{O}_{5}{ }^{+}\right.$, see Figure 7 , blue trace). PTR-ToFMS resolution of 5000 and multipeak Gaussian fit ensure good measurement accuracy.

The method described here shows for the first time that spin traps have been successfully applied to directly capture Criegee intermediates of atmospherically relevant large alkenes in the gas phase.

\section{CONCLUSIONS}

We report, for the first time, the unambiguous identification and quantification of $\alpha$-pinene CIs through the detection of their adducts with spin traps. We developed a new method to detect and quantify CIs in the gas phase by stabilization with spin traps and analysis with PTR-ToF-MS. This new technique offers a method to characterize highly reactive and atmospherically relevant radical intermediates in situ and under temperature and pressure conditions relevant for the lower troposphere, albeit at a very high concentration of olefinic precursor due to the otherwise very slow kinetic of the ozonolysis reaction. We show that carbonyl oxides efficiently react through cycloaddition to the nitrone group of the spin traps and the nonradical adducts that form are stable enough to allow full characterization with HPLC-MS and NMR and online detection with PTR-ToF-MS. The method has a detection limit of $0.03 \mathrm{ppb}$ and repeatability (between different experiments) of $\pm 0.5 \mathrm{ppb}$ for $\alpha$-pinene CIs, offering a costeffective, laboratory-based technique to study highly reactive radical intermediates. The method presented here has the 
potential to be used to detect a wide range of CIs synthesized from different organic precursors, opening up the possibility of detecting multiple CIs simultaneously in a complex, multiprecursor system to simulate real-atmosphere processes; however, challenges still remain to quantify CIs at atmospheric concentrations. The method has the potential to be used for quantification of CIs, although specific calibration procedures need to be developed to improve quantification accuracy, as calibration standards are currently not available. The method proposed here is potentially applicable to many different organic radical species opening up the possibility of characterizing these highly reactive and short-lived species in many areas of physical and organic chemistry where radical reactions are studied and deployed.

\section{ASSOCIATED CONTENT}

\section{S Supporting Information}

The Supporting Information is available free of charge on the ACS Publications website at DOI: 10.1021/jacs.6b10981.

Additional experimental details and results, including 5 tables, 20 figures, absolute energies (in Hartrees), and coordinates of the atoms of all the molecules whose geometries were optimized (PDF)

\section{AUTHOR INFORMATION}

\section{Corresponding Authors}

*chiara.giorio@atm.ch.cam.ac.uk

*markus.kalberer@atm.ch.cam.ac.uk

\section{ORCID $\odot$}

Chiara Giorio: 0000-0001-7821-7398

Francesco Tampieri: 0000-0003-1474-867X

\section{Present Address}

"Aix Marseille Univ, CNRS, LCE, Marseille, France

\section{Notes}

The authors declare no competing financial interest.

\section{ACKNOWLEDGMENTS}

This work was funded by the European Research Council (ERC starting grant 279405). Authors thank four anonymous reviewers for helpful revision of the manuscript.

\section{REFERENCES}

(1) Mauldin, R. L., III; Berndt, T.; Sipilä, M.; Paasonen, P.; Petäjä, T.; Kim, S.; Kurtén, T.; Stratmann, F.; Kerminen, V.-M.; Kulmala, M. Nature 2012, 488 (7410), 193-196.

(2) Vereecken, L. Science (Washington, DC, U. S.) 2013, 340 (6129), 154-155.

(3) Criegee, R. Angew. Chem., Int. Ed. Engl. 1975, 14 (11), 745-752.

(4) Osborn, D. L.; Taatjes, C. A. Int. Rev. Phys. Chem. 2015, 34 (3), 309-360.

(5) Kalinowski, J.; Heinonen, P.; Kilpeläinen, I. A.; Rasanen, M.; Gerber, R. B. J. Phys. Chem. A 2014, 119, 2318.

(6) Cremer, D.; Gauss, J.; Kraka, E.; Stanton, J. F.; Bartlett, R. J. Chem. Phys. Lett. 1993, 209 (5-6), 547-556.

(7) Miliordos, E.; Ruedenberg, K.; Xantheas, S. S. Angew. Chem., Int. Ed. 2013, 52 (22), 5736-5739.

(8) Sander, W. Angew. Chem., Int. Ed. 2014, 53, 362-364.

(9) Cox, R. A.; Penkett, S. A. Nature 1971, 230, 321-322.

(10) Boy, M.; Mogensen, D.; Smolander, S.; Zhou, L.; Nieminen, T.; Paasonen, P.; Plass-Dülmer, C.; Sipilä, M.; Petäjä, T.; Mauldin, R. L.; Berresheim, H.; Kulmala, M. Atmos. Chem. Phys. 2013, 13 (7), 38653879.
(11) Hall, W. A., IV; Johnston, M. V. J. Am. Soc. Mass Spectrom. 2012, 23 (6), 1097-1108.

(12) Kourtchev, I.; Giorio, C.; Manninen, A.; Wilson, E.; Mahon, B.; Aalto, J.; Kajos, M.; Venables, D.; Ruuskanen, T.; Levula, J.; Loponen, M.; Connors, S.; Harris, N.; Zhao, D.; Kiendler-Scharr, A.; Mentel, T.; Rudich, Y.; Hallquist, M.; Doussin, J.-F.; Maenhaut, W.; Bäck, J.; Petãjä, T.; Wenger, J.; Kulmala, M.; Kalberer, M. Sci. Rep. 2016, 6, 35038.

(13) Ehn, M.; Thornton, J. A.; Kleist, E.; Sipilä, M.; Junninen, H.; Pullinen, I.; Springer, M.; Rubach, F.; Tillmann, R.; Lee, B.; LopezHilfiker, F.; Andres, S.; Acir, I.-H.; Rissanen, M.; Jokinen, T.; Schobesberger, S.; Kangasluoma, J.; Kontkanen, J.; Nieminen, T.; Kurtén, T.; Nielsen, L. B.; Jørgensen, S.; Kjaergaard, H. G.; Canagaratna, M.; Dal Maso, M.; Berndt, T.; Petäjä, T.; Wahner, A.; Kerminen, V.-M.; Kulmala, M.; Worsnop, D. R.; Wildt, J.; Mentel, T. F. Nature 2014, 506, 476-479.

(14) Tröstl, J.; Chuang, W. K.; Gordon, H.; Heinritzi, M.; Yan, C.; Molteni, U.; Ahlm, L.; Frege, C.; Bianchi, F.; Wagner, R.; Simon, M.; Lehtipalo, K.; Williamson, C.; Craven, J. S.; Duplissy, J.; Adamov, A.; Almeida, J.; Bernhammer, A.-K.; Breitenlechner, M.; Brilke, S.; Dias, A.; Ehrhart, S.; Flagan, R. C.; Franchin, A.; Fuchs, C.; Guida, R.; Gysel, M.; Hansel, A.; Hoyle, C. R.; Jokinen, T.; Junninen, H.; Kangasluoma, J.; Keskinen, H.; Kim, J.; Krapf, M.; Kürten, A.; Laaksonen, A.; Lawler, M.; Leiminger, M.; Mathot, S.; Möhler, O.; Nieminen, T.; Onnela, A.; Petäjä, T.; Piel, F. M.; Miettinen, P.; Rissanen, M. P.; Rondo, L.; Sarnela, N.; Schobesberger, S.; Sengupta, K.; Sipilä, M.; Smith, J. N.; Steiner, G.; Tomè, A.; Virtanen, A.; Wagner, A. C.; Weingartner, E.; Wimmer, D.; Winkler, P. M.; Ye, P.; Carslaw, K. S.; Curtius, J.; Dommen, J.; Kirkby, J.; Kulmala, M.; Riipinen, I.; Worsnop, D. R.; Donahue, N. M.; Baltensperger, U. Nature 2016, 533 (7604), 527531.

(15) Mentel, T. F.; Springer, M.; Ehn, M.; Kleist, E.; Pullinen, I.; Kurtén, T.; Rissanen, M.; Wahner, A.; Wildt, J. Atmos. Chem. Phys. 2015, 15 (12), 6745-6765.

(16) Harrison, R. M.; Yin, J.; Tilling, R. M.; Cai, X.; Seakins, P. W.; Hopkins, J. R.; Lansley, D. L.; Lewis, A. C.; Hunter, M. C.; Heard, D. E.; Carpenter, L. J.; Creasey, D. J.; Lee, J. D.; Pilling, M. J.; Carslaw, N.; Emmerson, K. M.; Redington, A.; Derwent, R. G.; Ryall, D.; Mills, G.; Penkett, S. A. Sci. Total Environ. 2006, 360 (1-3), 5-25.

(17) Ryzhkov, A. B.; Ariya, P. A. Chem. Phys. Lett. 2003, 367 (3-4), 423-429.

(18) Ryzhkov, A. B.; Ariya, P. A. Chem. Phys. Lett. 2006, 419 (4-6), 479-485.

(19) Newland, M. J.; Rickard, A. R.; Vereecken, L.; Muñoz, A.; Ródenas, M.; Bloss, W. J. Atmos. Chem. Phys. 2015, 15 (16), 95219536.

(20) Newland, M. J.; Rickard, A. R.; Alam, M. S.; Vereecken, L.; Muñoz, A.; Ródenas, M.; Bloss, W. J. Phys. Chem. Chem. Phys. 2015, 17 (6), 4076-4088.

(21) Berndt, T.; Voigtländer, J.; Stratmann, F.; Junninen, H.; Mauldin, R. L., III; Sipilä, M.; Kulmala, M.; Herrmann, H. Phys. Chem. Chem. Phys. 2014, 16 (36), 19130-19136.

(22) Berresheim, H.; Adam, M.; Monahan, C.; O’Dowd, C.; Plane, J. M. C.; Bonn, B.; Rohrer, F. Atmos. Chem. Phys. Discuss. 2014, 14 (1), $1159-1190$

(23) Taatjes, C. A.; Meloni, G.; Selby, T. M.; Trevitt, A. J.; Osborn, D. L.; Percival, C. J.; Shallcross, D. E. J. Am. Chem. Soc. 2008, 130 (36), 11883-11885.

(24) Welz, O.; Savee, J. D.; Osborn, D. L.; Vasu, S. S.; Percival, C. J.; Shallcross, D. E.; Taatjes, C. A. Science (Washington, DC, U. S.) 2012, 335 (6065), 204-207.

(25) Chao, W.; Hsieh, J.-T.; Chang, C.-H.; Lin, J. J.-M. Science (Washington, DC, U. S.) 2015, 347 (6223), 751-754.

(26) Lewis, T. R.; Blitz, M. A.; Heard, D. E.; Seakins, P. W. Phys. Chem. Chem. Phys. 2015, 17 (7), 4859-4863.

(27) Taatjes, C. A.; Welz, O.; Eskola, A. J.; Savee, J. D.; Scheer, A. M.; Shallcross, D. E.; Rotavera, B.; Lee, E. P. F.; Dyke, J. M.; Mok, D. K. W.; Osborn, D. L.; Percival, C. J. Science 2013, 340 (6129), 177-180. 
(28) Chhantyal-Pun, R.; Davey, A.; Shallcross, D. E.; Percival, C. J.; Orr-Ewing, A. J. Phys. Chem. Chem. Phys. 2015, 17 (5), 3617-3626.

(29) Kidwell, N. M.; Li, H.; Wang, X.; Bowman, J. M.; Lester, M. I. Nat. Chem. 2016, 8 (5), 509-514.

(30) Fang, Y.; Liu, F.; Barber, V. P.; Klippenstein, S. J.; McCoy, A. B.; Lester, M. I. J. Chem. Phys. 2016, 144 (6), 61102.

(31) Novelli, A.; Vereecken, L.; Lelieveld, J.; Harder, H. Phys. Chem. Chem. Phys. 2014, 16 (37), 19941-19951.

(32) Su, Y.-T.; Huang, Y.-H.; Witek, H. A.; Lee, Y.-P. Science 2013, 340 (6129), 174-176.

(33) Ahrens, J.; Carlsson, P. T. M.; Hertl, N.; Olzmann, M.; Pfeifle, M.; Wolf, J. L.; Zeuch, T. Angew. Chem., Int. Ed. 2014, 53 (3), 715719.

(34) Kim, S.; Guenther, A.; Lefer, B.; Flynn, J.; Griffin, R.; Rutter, A. P.; Gong, L.; Cevik, B. K. Environ. Sci. Technol. 2015, 49, 3383.

(35) Nguyen, T. B.; Tyndall, G. S.; Crounse, J. D.; Teng, A. P.; Bates, K. H.; Schwantes, R. H.; Coggon, M. M.; Zhang, L.; Feiner, P.; Miller, D. O.; Skog, K. M.; Rivera-Rios, J. C.; Dorris, M.; Olson, K. F.; Koss, A.; Wild, R. J.; Brown, S. S.; Goldstein, A. H.; de Gouw, J. A.; Brune, W. H.; Keutsch, F. N.; Seinfeld, J. H.; Wennberg, P. O. Phys. Chem. Chem. Phys. 2016, 18 (15), 10241-10254.

(36) Anglada, J. M.; González, J.; Torrent-Sucarrat, M. Phys. Chem. Chem. Phys. 2011, 13, 13034-13045.

(37) Anglada, J. M.; Solé, A. Phys. Chem. Chem. Phys. 2016, 18 (26), 17698-17712.

(38) Vereecken, L.; Rickard, A. R.; Newland, M. J.; Bloss, W. J. Phys. Chem. Chem. Phys. 2015, 17 (37), 23847-23858.

(39) Beames, J. M.; Liu, F.; Lu, L.; Lester, M. I. J. Am. Chem. Soc. 2012, 134 (49), 20045-20048.

(40) Pryor, W. A.; Prier, D. G.; Church, D. F. J. Am. Chem. Soc. 1983, 105 (9), 2883-2888.

(41) Pryor, W. A. Free Radical Biol. Med. 1994, 17 (5), 451-465.

(42) Stipa, P. Tetrahedron 2013, 69 (23), 4591-4596.

(43) Nakagawa, S. Anal. Sci. 2013, 29 (3), 377-380.

(44) Samuni, A.; Carmichael, A. J.; Russo, A.; Mitchell, J. B.; Riesz, P. Proc. Natl. Acad. Sci. U. S. A. 1986, 83 (20), 7593-7597.

(45) Shoji, T.; Li, L.; Abe, Y.; Ogata, M.; Ishimoto, Y.; Gonda, R.; Mashino, T.; Mochizuki, M.; Uemoto, M.; Miyata, N. Anal. Sci. 2007, 23 (2), 219-221.

(46) Suarez-Bertoa, R.; Saliu, F.; Bruschi, M.; Rindone, B. Tetrahedron 2012, 68 (39), 8267-8275.

(47) Matsumoto, K.; Nyui, M.; Kamibayashi, M.; Ozawa, T.; Nakanishi, I.; Anzai, K. J. Clin. Biochem. Nutr. 2011, 50 (1), 40-46.

(48) Gordon, S. A.; Chughtai, A. R.; Smith, D. M. Am. Lab. 2000, 32 (9), 12-13.

(49) Rakness, K.; Gordon, G.; Langlais, B.; Masschelein, W.; Matsumoto, N.; Richard, Y.; Robson, C. M.; Somiya, I. Ozone: Sci. Eng. 1996, 18 (3), 209-229.

(50) Duling, D. R. J. Magn. Reson., Ser. B 1994, 104, 105-110.

(51) Ahlrichs, R.; Bär, M.; Häser, M.; Horn, H.; Kölmel, C. Chem.

Phys. Lett. 1989, 162 (3), 165-169.

(52) Becke, A. D. Phys. Rev. A: At., Mol., Opt. Phys. 1988, 38 (6), 3098-3100.

(53) Perdew, J. P. Phys. Rev. B: Condens. Matter Mater. Phys. 1986, 33

(12), 8822-8824.

(54) Becke, A. D. J. Chem. Phys. 1993, 98 (7), 5648-5652.

(55) Lee, C.; Yang, W.; Parr, R. Phys. Rev. B: Condens. Matter Mater. Phys. 1988, 37 (2), 785-789.

(56) Stephens, P.; Devlin, F.; Chabalowski, C.; Frisch, M. J. Phys. Chem. 1994, 98 (45), 11623-11627.

(57) Eichkorn, K.; Weigend, F.; Treutler, O.; Ahlrichs, R. Theor. Chem. Acc. 1997, 97 (1-4), 119-124.

(58) Schäfer, A.; Huber, C.; Ahlrichs, R. J. Chem. Phys. 1994, 100 (8), 5829.

(59) Jensen, F. Introduction to computational chemistry; John Wiley \& Sons: Chichester, England, 2007.

(60) Boys, S. F.; Bernardi, F. Mol. Phys. 1970, 19 (4), 553-566.

(61) Zhao, J.; Zhang, R. Atmos. Environ. 2004, 38 (14), 2177-2185.

(62) Buettner, G. R. Free Radical Biol. Med. 1987, 3, 259-303.
(63) Hill, H. A. O.; Thornalley, P. J. Inorg. Chim. Acta 1982, 67, L35-L36.

(64) Domingues, P.; Domingues, M. R. M.; Amado, F. M. L.; FerrerCorreia, A. J. J. Am. Soc. Mass Spectrom. 2001, 12 (11), 1214-1219.

(65) Reis, A.; Domingues, M. R. M.; Amado, F. M. L.; Ferrer-Correia, A. J. V; Domingues, P. J. Am. Soc. Mass Spectrom. 2003, 14 (11), $1250-1261$

(66) Guo, Q.; Qian, S. Y.; Mason, R. P. J. Am. Soc. Mass Spectrom. 2003, 14 (8), 862-871.

(67) Vereecken, L.; Francisco, J. S. Chem. Soc. Rev. 2012, 41 (19), 6217-6708

(68) Zhang, D.; Zhang, R. J. Chem. Phys. 2005, 122 (11), 114308.

(69) Chuong, B.; Zhang, J.; Donahue, N. M. J. Am. Chem. Soc. 2004, 126 (39), 12363-12373.

(70) Adam, W.; Briviba, K.; Duschek, F.; Golsch, D.; Kiefer, W.; Sies, H. J. Chem. Soc., Chem. Commun. 1995, 18, 1831-1832.

(71) Liu, F.; Fang, Y.; Kumar, M.; Thompson, W. H.; Lester, M. I. Phys. Chem. Chem. Phys. 2015, 17 (32), 20490-20494.

(72) Khan, N.; Wilmot, C. M.; Rosen, G. M.; Demidenko, E.; Sun, J.; Joseph, J.; O'Hara, J.; Kalyanaraman, B.; Swartz, H. M. Free Radical Biol. Med. 2003, 34 (11), 1473-1481.

(73) Liu, K. J.; Jiang, J. J.; Ji, L. L.; Shi, X.; Swartz, H. M. Res. Chem. Intermed. 1996, 22 (5), 499-509. 